Article

\title{
A Comprehensive View of Expression Profiles Dynamics of Capsaicinoid Biosynthesis-Related Genes during Pepper Fruit Development and under MeJA Treatment
}

\author{
Minghua Deng ${ }^{1,2,3, \dagger}$, Jinfen Wen ${ }^{3,4, \dagger}$, Kai Zhao ${ }^{1, \dagger}$, Jinlong Huo ${ }^{5, \dagger}$, Zhuqing Zhang ${ }^{2}$, \\ Haishan Zhu ${ }^{1}$ and Xuexiao Zou ${ }^{2, *}$ \\ 1 College of Horticulture, Yunnan Agricultural University, Kunming 650224, China; \\ dengminghua2013@163.com (M.D.) \\ 2 Hunan Academy of Agricultural Science, Changsha 420125, China \\ 3 College of Agriculture and Life Sciences, Cornell University, Ithaca, NY 14853, USA \\ 4 Faculty of Architecture and City Planning, Kunming University of Science and Technology, Kunming 650500, China \\ 5 Faculty of Animal Science and Technology, Yunnan Agricultural University, Kunming 650224, China \\ * Correspondence: pepper_breed@163.com \\ $\dagger$ Those authors contributed equally to this work.
}

\begin{abstract}
Background: Capsaicinoid are a group of compounds and widely used in the food, medical, and pharmaceutical industries. Capsaicinoid are unique synthesized and accumulated in the pepper fruits. MeJA can enhance the capsaicinoid production. Temporal and spatial expression of capsaicinoid biosynthetic genes are helpful to understand the molecular mechnism of capsaicinoid biosynthesis in the fruits of pepper. Although some of the capsaicinoid biosynthetic genes in pepper have been identified, the expression of these genes at different developing stages of fruit has not been systemically investigated, and little is known about the molecular basis of MeJA inducing capsaicinoid biosynthesis. Results: HPLC study revealed that the capsaicinoid accumulation in the developing fruit of pepper initially appeared at 24 DAP (day after pollination), was actively development at 36 DAP and peaked at 48 DAP. 11 genes that encoded enzymes involved in capsaicinoid biosynthesis were isolated and characterized. Gene expression with quantitative reverse-transcription polymerase chain reaction analysis demonstrated that the $\mathrm{CaCS}$ was unique expressed in placenta and the other 10 genes were expressed in all selected tissues and 9 of 11 genes (except $\mathrm{CaCa} 4 \mathrm{H}$ and $\mathrm{CaCa} 3 \mathrm{H}$ ) were strongly expressed in placenta tissue. Spatial expression analysis demostrated that the 11 gene could be collectively grouped into four categories based on the patterns of relative expression of the genes during fruit development. Category I has 2 and they displayed a bell-shaped expression pattern with the peak expression at 24 DAP, Category II contains 5 genes and expression of the 5 genes was constantly increased from 0 to 36 DAP and peaked at 36 DAP. Category III comprises of 2 genes and both genes reached the peak at 48 DAP. Category IV consists of 2 genes and they showed a high expression at 36 and $48 \mathrm{DAF}$, but unexpressed from 0 to
\end{abstract}


12 DAP. The gene expressions of the 11 genes were up-regulated by MeJA. 3 genes showed a high expression at $24 \mathrm{~h} ; 4$ genes reached the peak at $12 \mathrm{~h}$; the top expression were observed at $18 \mathrm{~h}$; The last one, CaACYase, achieved the highest level at $8 \mathrm{~h}$. Conclusion: The biosynthesis of capsaicinoid in pepper fruit is developmentally regulated. The expression of the majority of capsaicinoid biosynthetic genes is highly consistent with the development accumulation of capsaicinoid in pepper fruit. These results not only provide the initial information on spatial and temporal expression of capsaicinoid biosynthetic genes in pepper developing fruit, but are also valuable to identify the MeJA-induced genes for capsaicinoid biosynthesis and accumulation during pepper fruit development.

Keywords: Capsicum annuum L.; capsaicinoid synthesis; gene expression; fruit development; MeJA

Pepper (Capsicum spp.) is a most economical vegetable in the world due to its high consumption [1]. The high demand of pepper fruits due to its pungent taste caused by a group of alkaloid compounds known as capsaicinoid [2]. These compounds are exclusively synthesized and accumulated in the fruit organ of pepper [3]. Capsaicinoid have been widely investigated and explored their usage in the food, medical, and pharmaceutical industries [4-6]. In addition, the role of capsaicinoid as anticancer, analgesic, antioxidant and antiarthritic properties has been validated [7-9].

There are more than 10 natural capsaicinoid analogs differing in length of the fatty acid chain [10]. Among them, capsaicin and dihydrocapsaicin are the most two predominant with $90 \%$ of the total capsaicinoid content in pepper [6]. The biosynthesis of these metabolite occurs in the placental epidermal cells and accumulates within blisters located on the surface of placenta. The accumulation of capsaicinoid start almost 20 days after pollination (DAP), and the maximum level report at 40-50 DAP [11-13].

The commen capsaicinoid biosynthetic pathway is outlined for better understanding of their biosynthesis (Fig.1) [14,15]. This pathway is complex and uses intermediates as precurses from two other independent pathways [16-20]. One is phenylpropanoid pathway, in which L-phenylalanine as the precursor render cinnamic acid, $p$-coumaric acid, caffeoyl-shikimate and feruloyl-CoA and subsquently vanillin and vanillylamine, by the action of the enzymes, such as CaPAL, CaCa4H, $\mathrm{CaCa} 3 \mathrm{H}, \mathrm{CaCOMT}$ and CapAMT in a series of reaction $[21,22]$. The second one is the branchedchain fatty acid pathway, in which leucine or valine is the precursors for the synthesis of 
$\alpha$-Isovaletate, 8-methylnonenoic acid, 8-methyl-6-nonenoyl-CoA, caralyzed by the enzymes including CaBCAT, CaKAS, CaACL, CaFAT and CaACYase [23]. Finally, producers are synthesized by condensation of vanillylamine and 8-methyl-6-nonenoyl-CoA with the caralylic action of CaCS enzyme [24].

The enzymes ebcoded by CaPAL, CaCa4H, CaCa3H, CaCOMT and CapAMT of phenylpropanoid pathway, were established by several authors [22]. Curry et al.[14] repoted cDNAs beloning to Pal, C4h, pAMT and Comt genes from a Capsicum chinense cv. Habanero cDNA library and documented that transcript of Pal, C4h, pAMT and Comt genes were accumulated in Habanero chili pepper mature fruit placentas. Stewart et al. [25] and Mazourek et al. [20] reported some enzymes that involved in capsaicinoid biosynthesis based on different experimental sources in the phenylpropanoid pathway.

The activities of enzymes in branchedchain fatty acid pathways had been measured and the corresponding genes were identified $[23,26]$. The differential expression analisis of the fatty acid synthase (FAS) genes Acll, FatA and Kas in Capsicum fruits were investigated and a positive relationship between the degree of pungency with transcript levels of these genes in placental tissue were established [23].

Employing gene silencing expression, del Rosario Abraham-Juáre et al. [27] observed that the infected plants with undetectable transcript levels had undetectable capsaicinoid levels. In this context, the roles of Comt, pAmt and Kas in capsaicinoid-biosynthesis were confirmed, the participations of these genes in capsaicinoid-biosynthesis were proven.

The key regulatory enzyme of capsaicinoid biosynthetic pathway is capsaicinoid synthase (CS) $[22,28,29]$. CS catalyzes the final condensation of vanillylamine and the branchedchain fatty acid [30]. Recently studies, Punl locus corresponding to the presence of capsaicinoid in chili pepper fruits was identified and a novel gene AT3 that co-localize with this locus was isolated and characterized [31]. In addition, Prasad et al. [32, 33] documented a 35-kDa CS able to catalyze the in vitro synthesis of capsaicin from vanillylamine and 8- methylnonenoic acid. A candidate gene Pun1 in C. annuum L. has been corrected with the accumulation of capsaicinoid [34]. The AT3-silenced pepper plants showed a reduction of in capsaicinoid content and a significant reduction in the expression of candidates genes ( $p A m t, B C A T$, Kas and $A c l$ ) involved in capsaicinoid biosynthesis [31].

In recent years, numerous studies have demonstrated that both biotic and abiotic elicitors such as $\mathrm{Ag}^{+}, \mathrm{Co}^{2+}, \beta$-aminobutyric acid (BABA), methyl jasmonate (MeAJ), and salicylic acid (SA) can stimulate biosynthesis of secondary bioactive components in plants [35-39 ]. Several studies have 
confirmed that MeJA can up-regulated the activities of CaPAL and CaCOMT and enhance capsaicin production in cell suspension cultures of Capsicum. [33, 37, 40].

In order to achieve a better understanding of the biosynthetic pathway of capsaicinoid metabolites, we systemically described the sequence homology, spatial and temporal expression, and expression behavioral changes of selected genes under MeJA treatment. The results could provide a comprehensively understanding the role of capsaicinoid biosynthetic pathway genes.

\section{Materials and methods}

\section{Plant material}

Nadao pepper (C. annuum var nadao), a very local hot pepper variety in Yunnan Province, was grown in experimental fields of Yunnan Agricultural University. In summer, different tissues (roots, stems, leaves, flowers, pericarps, placentas and seeds) were obtained for analysis purposes. The developing fruits were harvested at different interval time after pollination $(0,12,24,36,48,60$ DAP). The fruit samples were carefully seperated into pericarps and placentas. All placentas were cut into small pieces and were instantly frozen in liquid nitrogen and stored at $-80^{\circ} \mathrm{C}$ until further processing.

\section{Separation and quantification of capsaicinoid}

The isolation and quanlification of capsaicinoid were performed according to Deng et al., [41]. The dried placentas power $(1 \mathrm{~g})$ was extracted with $25 \mathrm{ml}$ of acetone shaken at room temperature for $4 \mathrm{~h}$ and filtered through a $0.45-\mathrm{mm}$ filter (Millex-HN, Millipore) and stored at $4^{\circ} \mathrm{C}$. A 10 -ul aliquot was analyzed in a Hitachi-Merck 6200 with mobile phape $\left(\mathrm{CH}_{3} \mathrm{OH}: \mathrm{H}_{2} \mathrm{O}=65: 35\right)$ and 1 $\mathrm{ml} / \mathrm{min}$ flow rate. The peaks was detected at $229 \mathrm{~nm}$ with retention times ( $8 \mathrm{~min}$ for capsaicin and $11 \mathrm{~min}$ for dihydrocapsaicin). Peak areas of capsaicin and dihydrocapsaicin were converted to ppm as described by Collins et al. [42].

\section{MeJA treatment}

MeJA, the key signaling molecule, modulate various physiological events during plant growth and development [43]. Fruit of $36 \mathrm{DAP}$ were treated with $150 \mu \mathrm{M}$ MeJA by continually spraying for $5 \mathrm{~min}$ in the greenhouse. The fruits were collected at $0,2,4,8,12,18,24$ and $36 \mathrm{~h}$ after treatment. As a control, fruits were sampled immediately before treatment. Three biology duplications of each sample (each sample containing three plants) were performed.

\section{RNA isolation and First-strand cDNA synthesis}

The total RNA was isolated from treated and untreated experiments according to (Deng et al. [44]. The first-strand cDNA was also synthesis as per instruction and phylogenetic analysis. 
The RT-PCR products were used as template for cloning of the full lenghs of $C a P A L, C a A C L$, CaACYase, CaBCAT, CaCa3H, CaCa4H, CaCOMT, CaFAT, CaKAS, CapAMT and CaCS genes using the reverse transcriptase polymerase chain reaction (RT-PCR) based on the sequences information of the Solanaceae plants and known highly homologous pepper ESTs. The primers design, PCR amplification reaction, the PCR products detection and sequencing of products were performed as described earlier [44]. All primers used in this research are listed in Table 1. The phylogenetic analysis was also carried out using same strategies as described earlier [44].

\section{Quantitative Real-time PCR (qRT-PCR) analysis}

Approximately $1 \mu \mathrm{g}$ of total RNA was treated with RNase-Free DNase I (TaKaRa, Dalian) to eliminate DNA contamination. The expression profiles of 11 genes were monitored by qRT-PCR analysis with protocols as described earlier [44]. All primers used for qRT-PCR in this research are listed in Table 1 . The expression levels were calculated by comparing the cycle threshold value $\left(\mathrm{C}_{\mathrm{t}}\right)$ for each gene to the $\mathrm{Ct}$ of the reference gene $\beta$-ACTIN. For the tissue specific expression assay, the expression of each gene was normalized to its expression in the placenta. For the developing fruit expression assay, the expression of each gene was normalized to its expression in the 24 DAP. For the MeJA elicitation experiments, the gene expression was normalized to that of the uninduced sample. Relative gene expression was calculated using the $2^{-\Delta \Delta \mathrm{Ct}}$ method [45].

Three repeated experiments, including internal controls and negative controls (reaction samples without cDNA templates), were conducted.

\section{Results}

\section{Temporal accumulation of total capsaicinoid content during fruit development}

This study showed that the total capsaicinoid content undetected in the first 12 DAP of development of the pepper fruit. The total capcaicinoid content was increased slowly from 24 (1.84 $\mathrm{mg} / \mathrm{g})$ to 36 DAP $(3.29 \mathrm{mg} / \mathrm{g})$. There was a rapid significant accumulation of total capsaicinoid from 36 to 48 DAP and reached the maximum level on 48 DAP $(10.06 \mathrm{mg} / \mathrm{g})$. After 48 DAP there was a significent reduction of total capsaicinoid content (29.5\% decrease) in fruit.

\section{Isolation and characterization of 11 full-length cDNA sequences involved in capsaicinoid biosynthesis}

The selected five genes of phenylpropanoid pathway were cloned and analysed. The results showed that CaPAL, CaCa4H, CaCa3H, CaCOMT and CapAMT contained a 2154, 1518, 1536, 1086 and 1380 bp ORF encoding 717, 505, 511, 361 and 459 aa residues respectively. The Mw and pI of the corresponding proteins were 77.912, 58.020, 57.981, 39.621, 50.929 kDa and 6.31, 9.25, $8.40,5.30,6.04$, respectively. 
CaBCAT, CaKAS, CaFAT, CaACL and CaACYase genes from branched-chain fatty acid biosynthesis pathway were cloned and analysed. The results showed that $C a B C A T, C a K A S$, CaFATA, CaACL and CaACYase contained 1158, 1467, 1116, 399 and 1371 nucleotide coding region and the predicted translation product of the coding region was 385, 488, 371, 132 and 456 amino acid protein, respectively. The $\mathrm{Mw}$ and $\mathrm{pI}$ of the protein encoded by five genes were 42.459, $52.405,41.942,14.000,51.089 \mathrm{kDa}$ and $8.34,7.98,6.48,5.16,5.52$, respectively.

$\mathrm{CaCS}$ gene was also cloned, analysed and showed that $C a C S$ contained a $1323 \mathrm{bp}$ ORF encoding 440 aa residues. The $\mathrm{Mw}$ and $\mathrm{pI}$ of corresponding protein are $49.296 \mathrm{kDa}$ and 6.52 , respectively.

\section{Sequence homology, and phylogenetic analysis of the predicted proteins}

The base composition of eleven genes were calculated and the results showed that the base composition were difference between the genes (table 2). The number of twenty kinds of amino acids, total number of negatively charged residues (Asp + Glu) and total number of positively charged residues (Arg + Lys) of the eleven proteins were also counted and the results showed they were varied between the proteins (table S1). At the same time, the formula, Ext. coefficient (extinction coefficients are in units of $\mathrm{M}^{-1} \mathrm{~cm}^{-1}$, at $280 \mathrm{~nm}$ measured in water), the instability index (II) and aliphatic index were predicted (table S2).

All of the eleven proteins do not have $\mathrm{N}$-terminal signal peptide and are non-secretory proteins. Four proteins (CaPAL, CaCOMT, CapAMT, CaKAS) were probably located in the plasma membrane with up to more than $70 \%$ probability and two $(\mathrm{CaCa} 4 \mathrm{H}$ and $\mathrm{CaCa} 3 \mathrm{H})$ of them were probably located in the endoplasmic reticulum with up to $68.5 \%$ and $82 \%$ probability. The predicted $\mathrm{CaCa} 4 \mathrm{H}$ and $\mathrm{CaCa} 3 \mathrm{H}$ proteins possessed one transmembrane helice at positions 5-24 aa and 2-24 aa. The other nine genes were not potential membrane proteins.

The secondary structure of eleven genes were predicted by SOPMA. The number of alpha helices, extended strands, beta turns and random coils were documented in the table 3. The conserved domains of the eleven genes were identified and documented that CaPAL, CaCOMT, CapAMT, CaKAS belong to lyase_I_like superfamily, Dimerization superfamily and AdoMet_MTase superfamily, AAT_I superfamily, cond_enzymes superfamily, respectively.

\section{Analysis of sequence identity and evolutionary relationships of eleven prediction pepper proteins}

Similarity comparison of the deduced eleven protein sequences revealed that the 5 proteins (CaPAL, $\mathrm{CaCa} 4 \mathrm{H}, \mathrm{CaCa} 3 \mathrm{H}, \mathrm{CaCOMT}$ and CapAMT) in the phenylpropanoid pathway showed high similarity with the PAL, Ca4H, Ca3H, COMT and pAMT of other plants, exhibiting 94\%, 95\%, 95\%, 85\% and 86\% identity to Solanum tuberosum (AGT63063), S. tuberosum (ABC69046), 
Withania somnifera (ADM47799), S. lycopersicum (XP_004235028) and S. lycopersicum (XP_004244777), respectively.

The results also indicated that the five proteins (CaBCAT, CaKAS, CaFAT, CaACL and CaACYase) in branched-chain fatty acid biosynthesis pathway shared over $91 \%, 87 \%, 90 \%, 90 \%$ and $74 \%$ sequences identity with the BCAT of $S$. tuberosum (XP_006356815), KAS of $S$. tuberosum (XP_006343829), FAT of S. lycopersicum (XP_004242408), ACL of S. lycopersicum (XP_004229194) and ACYase of S. tuberosum (XP_006345840).

The predicted CaCS protein had no high homologous proteins of species outside the Capsicum genus, but it exhibited $99 \%$ identity with the acyltransferase proteins of $C$. frutescence (AAV66308) and C. chinense (AAV66309).

The phylogenetic tree analysis revealed that the 5 proteins $(\mathrm{CaPAL}, \mathrm{CaCa} 4 \mathrm{H}, \mathrm{CaCa} 3 \mathrm{H}$, CaCOMT and CapAMT) in the phenylpropanoid pathway had a closer genetic relationship with the PAL of S. tuberosum (AGT63063), Ca4H of S. tuberosum (ABC69046), Ca3H of W. somnifera (ADM47799), COMT of S. lycopersicum (XP_004235028) and pAMT of S. lycopersicum (XP_004244777), respectively, than with those of other species. The results also indicated that five proteins (CaBCAT, CaKAS, CaFAT, CaACL and CaACYase) in branched-chain fatty acid biosynthesis pathway were closely related to BCAT of S. tuberosum (XP_006356815), KAS of $S$. tuberosum (XP_006343829), FAT of S. lycopersicum (XP_004242408), ACL of S. lycopersicum (XP_004229194) and ACYase of S. tuberosum (XP_006345840), respectively, than to those of other species.

The predicted amino acid sequence of $\mathrm{CaCS}$ exhibited an extreme similarity with the corresponding enzymes (acyltransferase) from other plants in the Capsicum species and was closely related to acyltransferase protein of $C$. frutescence (AAV66308) and C. chinense (AAV66309).

\section{Spatial expression of capsaicinoid biosynthetic pathway gene in different tissues}

The CapAMT, CaKAS and CaCYase were highly expressed in placenta, weakly expressed in the other six tissues; The CaPAL, CaCOMT, CaFAT, CaACL, CaBCAT were strongly expressed in placenta as well seed, moderately or weakly expressed in the other five selected tissues; The $\mathrm{CaCa} 4 \mathrm{H}$ and $\mathrm{CaCa} 3 \mathrm{H}$ were weakly expressed in placenta; The $\mathrm{CaCS}$ was unique expressed in placenta. In conclusion, 9 of 11 genes (except $\mathrm{CaCa} 4 \mathrm{H}$ and $\mathrm{CaCa} H$ ) were strongly expressed in placenta, indicated their achive participtation in capsaicinoid biosynthesis (Fig. 2).

Transcription profile at pepper fruit development

Based on patterns of relative expression of genes at different developmental stages, the eleven genes could be divided into four categories (Figure 3). Category I has 2 genes ( $\mathrm{CaPAL}$ and $\mathrm{CaCa} 4 \mathrm{H}$ ) 
and they displayed a bell-shaped pattern of expression, which showed a constant increase in gene expression from 0 to 36 DAP and had peak expression at 24 DAP, but low expression at 60 DAP (Figure 3 I). Category II comprises of 5 genes including CaCOMT, CapAMT, CaKAS, CaFAT and CaACL and they showed a significantly increase in gene expression from 0 to $36 \mathrm{DAP}$, which peaked at 36 DAP (Figure 3 II). Category III contains $\mathrm{CaCa} 3 \mathrm{H}$ and $\mathrm{CaBCAT}$ genes and both genes reached the maximum expression at 48 DAP (Figure 3 III). Category IV includes 2 genes, $C a C S$ and CaACYase, and both of them displayed a high expression at 36 and 48 DAF, but unexpressed at 0 and 12 DAP (Figure 3 IV).

\section{Gene transcription profile by MeJA treatment}

The expression pattern of capsaicinoid biosynthetic pathway genes in selected sample after MeJA exposure was shown in Figure 4. MeJA up-regulated the CaPAL, CapAMT, CaBCAT expression and reached maximum at $24 \mathrm{~h}$ after treatment. The expression of $\mathrm{CaCa} 4 \mathrm{H}, \mathrm{CaCa} 3 \mathrm{H}$ and CaACL increased slightly at 2 and $4 \mathrm{~h}$, increased significantly at $12 \mathrm{~h}$, and peaked at the $18 \mathrm{~h}$, then decreased. The expressions of $C a C O M T, C a K A S, C a F A T$ and $C a C S$ were up-graduated and reached the highest level at the $12 \mathrm{~h}$, and then decreased. Slight up-regulation was observed for CaACYase with MeJA treatment, reaching highest level at $8 \mathrm{~h}$ and then decreased.

These results showed that selected genes in the capsaicinoid biosynthetic pathway were responsive to MeJA elicitation positively at transcription level with slight up-regulation.

\section{Discussion}

Capsaicinoid is well known secondary metabolites in pepper (specifically in placenta) [11]. We investigated a time-course for fruits development and capsaicinoid accumulation during pepper fruit development. The course of fruit development from flower pollination to a mature fruit takes about 60 d. After 48 DAP pepper fruits seem to be mature and begin turn-red color. Our observation is consistent with previous studies $[11,12,17]$. During the first 12 DAP, the capsaicinoid were undetectable. From 24 DAP to 48 DAP, the capsaicinoid were biosynthesised and accumulated. The capsaicinoid declined slightly during the natural senescence of pepper fruit. It has been reported that capsaicinoid start to synthesize and accumulate in the fruits 20 DAP, and reached the maximum level in 40-50 DAP [13]. Our confirmed the general observation that biosynthesis of capsaicinoid usually occurred at the middle stage during the development of fruit.

Investigation the instantaneous expression profiles of genes associated capsaicinoid biosynthesis within the developing fruits contributes to understand the molecular basis of capsaicinoid accumulation [3]. In the studies, it is unsurprised the 10 of 11 genes (except $C a C S$ ) 
were expressed within different tissues in pepper (Figure 2), since phenylpropanoid pathway and branchedchain fatty acid pathways could be found in all tissues in plants. 8 of these 10 genes (except $\mathrm{CaCa} 3 \mathrm{H}$ and $\mathrm{CaCa} 4 \mathrm{H}$ ) were highly expressed in the placenta tissue and weakly expressed in root, stem, leaf, flower and pericarp (Figure 2), indicating involved in capsaicinoid biosynthesis. The $C a C S$ gene, the last gene responsible for the condensation reaction between vanillylamine and 8-methyl-nonenoic acid in the capsaicinoid synthetic pathway, expressed in the placenta specifically (Figure 2). Capsaicinoid were synthesized and accumulated only in the placenta tissue of pepper fruit [29]. Our results supported the previously proposed capsaicinoid biosynthetic pathway [3, 17].

Many researches have reported that capsaicinoid biosynthesis genes which exhibited various temporal expression patterns at the different stages of developing pepper fruits $[3,11,17,43]$. In our research, the 11 genes associated with capsaicinoid biosynthesis presented various temporal expression patterns (Figure 2), suggesting their functional complex and specificity temporally at the time-course of fruit development. All the 11 genes were highly expressed within developing fruit, and exhibited an S-shaped pattern. It indicated that the expression of these genes was closely corrected with capsaicinoid accumulation. Probably the high transcripts of those genes would be the mechanism for maintaining or meeting the demand of capsaicinoid biosynthesis in developing pepper fruits.

6 genes (CaCOMT, CapAMT, CaKAS, CaACL, CaFAT and CaACYase) were highly expressed in the middle period of pepper fruit development and peaked at the 4th stages (36 DAP), earlier than the maximum capsaicinoid accumulation (48 DAP); The possible reasons were that these genes are located in the upstream of capsaicinoid biosynthesis. CaPAL and $\mathrm{CaCa} 4 \mathrm{H}$ are the first two genes in phenylpropanoid pathway; they highly increasing expressed at the early three stages of pepper fruits development (0-24 DAP) and exhibited a down-regulated expression pattern at the last three stages. It has been speculated that capsaicinoid might exhibited a down-regulated function in the capsaicinoid biosynthetic pathway as a feedback inhibitor [16]. The immature green pepper fruit placenta tissues immersed in several capsaicin solutions $(0,0.15,0.3$ or $0.6 \mathrm{mg} \mathrm{ml}-1)$ resulted a drastic decreasing $(* 50 \%$ compared with control) [46]. A gene post-transcriptional regulation might be the reason of the lack of a correlation between maximal expression level of $\mathrm{CaPAL}$ and $\mathrm{CaCa} 4 \mathrm{H}$ and capsaicinoid concentrations.

MeJA has been shown to play an important role inducing the accumulation of a wide range of plant secondary metabolites, such as lignin, phytoalexins, flavonoids, pigments, isoprenoids, alkaloids, phenylpropanoids, terpenes [3, 38, 39, 47, 48]. A higher level of capsaicinoid production in cell suspension after treatment with MeJA has also been observed [37, 40, 49]. 
Our study showed that $C a P A L, C a p A M T$ and $C a B C A T$ were up-regulated after MeJA treatment as compared to the control, achieved the highest level at $24 \mathrm{~h}$ treatment. Our results also showed that $\mathrm{CaCa} 4 \mathrm{H}, \mathrm{CaCa} \mathrm{HH}$ and $\mathrm{CaACL}$ genes transcriptions began to increased after MeJA elicitation, peaked at 18 h. Expression levels of CaCOMT, CaKAS, CaFAT and CaCS were induced after elicitation with MeJA and reached the top at $12 \mathrm{~h}$. Transcript levels of CaACYase increased and the highest level were achieved at $8 \mathrm{~h}$ after MeJA treatment. The up-regulated expression of these genes would be corresponding with the increased capsaicinoid accumulation by MeJA treatment.

$C a C S$ is the most important candidate gene for capsaicinoid synthase in the capsaicinoid biosynthesis pathway. Numerous study have verified that $\mathrm{CaCS}$ gene was tissue-specific expression in placenta tissue [24, 28]; The expression of $C a C S$ gene could not be detected in the early development stages, and highly expressed in the color-red turn stage of pepper fruit [11, 30, 32 ]; The expression patterns were similar to the capsaicinoid accumulation in the pepper fruit development; $C a C S$ can be overexpressed by 6-fold, corresponding to enhanced levels of capsaicin (6.15-fold) by MeJA treatment [33]. Our results here were similar to the reports of [11, 24, 28, 30, 32, 33], suggesting that CaCS is a key enzyme, it does represent alimiting step in capsaicinoid biosynthetic pathway.

CaPAL is an important target for metabolic regulation in capsaicinoid biosynthesis [22]. Some researches have demonstrated that CaPAL played an important role in capsaicinoid synthesis. Our work here also showed that $C a P A L$ was highly expressed in the placenta, the expression pattern was approximately positively correlated to the capsaicinoid content, and was highly up-regulated by MeJA treatment. Hence, CaPAL could be considered as one of the key genes in capsaicinoid biosynthetic pathway.

In recently, CapAMT has been isolated and confirmed to be an important gene in the phenylpropanoid pathway [26, 27, 31 ]. In our research, highly expressed in the placenta tissue, expression pattern similar to the tendency of capsaicinoid accumulation and significently up-regulated expression profiles were observed. Therefore, CapAMT could be also considered as another key gene in further promoting capsaicinoid biosynthesis.

\section{Author Contributions}

This study was conceived by Z-XX. The plant material preparation were carried out Z-ZQ and D-MH, Z-K and H-JL performed the q-PCR. D-MH, W-JL and Z-HS analyzed the data. D-MH and W-JF drafted the manuscript. Z-XX revised the manuscript. All authors read and approved the final manuscript. 


\section{Acknowledgements}

This study was supported by National Natural Science Foundation of China (Grant No. 31160394, 31560556).

\section{References}

1. Zou, X. X. China Capsicum. Beijing: China Agricultural Press, (in Chinese), 2002.

2. Bosland, P. W., Coon, D., Reeves, G. 'Trinidad Moruga Scorpion' pepper is the world's hottest measured chile pepper at more than two million Scoville heat units. HortTechnology 2012, 22, 534-538.

3. Kehie, M., Kumaria, S., Tandon, P., Ramchiary, N. Biotechnological advances on in vitro capsaicinoid biosynthesis in Capsicum: a review. Phytochem. Rev. 2015, 14, 189-201

4. Cuevas-Glory, L. F., Sosa-Moguel, O., Pino, J., Sauri-Duch, E. GC-MS characterization of volatile compounds in Habanero pepper (Capsicum chinense Jacq.) by optimization of heads pace solid-phase Microextraction conditions. Food Anal. Methods 2015, 8, 1005-1013.

5. Ludy, M. J., Moore, G. E., Mattes, R. D. The effects of capsaicin and capsiate on energy balance: Critical review and meta-analyses of studies in humans. Chem. Senses 2012, 37, 103-121.

6. Luo, X. J., Peng, J., Li, Y. J. Recent advances in the study on capsaicinoid and capsinoids. Eur. J. Pharmacol. 2011, 650, 1-7.

7. Korkutata, N. F., Kavaz, A. (2015). A comparative study of ascorbic acid and capsaicinoid contents in red hot peppers (Capsicum annum L.) grown in southeastern anatolia region. Int. J. Food Prop. 2015, 18, 725-734

8. Lau, J. K., Brown, K. C., Dom, A. M., Witter, T. R., Thorhill, B. A., Crabtree, C. C., et al. Capsaicin induces apoptosis in human small cell lung cancer via the TRPV6 receptor and the calpain pathway. Apoptosis 2014, 19, 1190-1201.

9. McCormack, P. Capsaicin dermal patch. Drugs 2010, 70, 1831-1842.

10. Blum, E., Mazourek, M., O'Connell, M. A., Curry, J., Thorup, T., Liu K., et al. (2003). Molecular mapping of capsaicinoid biosynthesis genes and quantitative trait loci analysis for capsaicinoid content in Capsicum. Theor. Appl. Genet. 2003, 108, 79-86.

11. Barbero, G. F., Ruiz, A. G., Liazid, A., Palma, M., Vera, J. C., Barroso, C. G. Evolution of total and individual capsaicinoid in peppers during ripening of the Cayenne pepper plant (Capsicum annuum L.). Food Chem, 2014, 153, 200-206

12. Iwai, K., Susuki, T., Fujiwaiki, H. Formation and accumulation of pungent principle of hot pepper fruits, capsaicin and its analogues, in Capsicum annuum var annuum cv. Karayatsubuse at different growth stages after flowering. Agric. Biol. Chem. 1979, 43: 2493-2498. 
13. Salgado-Garciglia, R., Ochoa-Alejo, N. Increased capsaicin content in PFP-resistant cells of chili pepper (Capsicum annuum L.). Plant Cell Rep. 1990, 8, 617-620

14. Curry, J., Aluru, M., Mendoza, M., Nevarez, J., Melendrez, M., O’Connell, M. A. Transcripts for possible capsaicinoid biosynthetic genes are differentially accumulated in pungent and non-pungent Capsicum spp. Plant Sci. 1999, 148:47-57

15. Islam, M. A., Sharma, S. S., Sinha, P., Negi, M. S., Neog, B., Tripathi, S. B. Variability in capsaicinoid content in different landraces of Capsicum cultivated in north-eastern India. Sci. Hortic-Amsterdam 2015, 183, 66-71

16. Aza-González, C., Núñez-Palenius, H. G., Ochoa-Alejo, N. Molecular biology of capsaicinoid biosynthesis in chili pepper (Capsicum spp.). Plant Cell Rep. 2011, 30, 695-706.

17. Keyhaninejad, N., Curry, J., Romero, J., O’Connell, M. A. Fruit specific variability in capsaicinoid accumulation and transcription of structural and regulatory genes in Capsicum fruit. Plant Sci. 2014, 215-216, 59-68

18. Kim, S., Park, M., Yeom, S. I., Kim, Y. M., Lee, J. M., Lee, H. A., et al. Genome sequence of the hot pepper provides insights into the evolution of pungency in Capsicum species. Nat Genet. 2014, 46, 270-278.

19. Liu, S., Li, W., Wu, Y., Chen, C., Lei, J. De novo transcriptome assembly in chili pepper (Capsicum frutescens) to identify genes involved in the biosynthesis of capsaicinoid. PLoS ONE 2013, 8, e48156.

20. Mazourek, M., Pujar, A., Borovsky, Y., Paran, I., Mueller L., Jahn, M. M. A dynamic interface for capsaicinoid symstems biology. Plant Physiol. 2009, 150, 1806-821.

21. Kobata, K., Sugawara, M., Mimura, M., Yazawa, S., Watanabe, T. Potent production of capsaicinoid and capsinoids by Capsicum peppers. J. Agric. Food Chem. 2013, 61, 11127-11132

22. Phimchan, P., Chanthai, S., Bosland, P. W., Techawonqstien B. Enzymatic changes in phenylalanine ammonia-lyase, cinnamic-4-hydroxylase, capsaicin synthase, and peroxidase activities in Capsicum under drought stress. J. Agric. Food Chem. 2014, 62, 7057-7062.

23. Aluru, M. R., Mazourek, M., Landry, L. G., Curry, L., Lahn M., O'Connell M. A. Differential expression of fatty acid synthase genes, Acl, Fat and Kas, in Capsicum fruit. J. Exp. Bot. 2003, $54,1655-1664$.

24. Han, K., Jeong, H.-J., Sung, J., Keum Y. S., Cho, M. C., Kim, J. H. et al. Biosynthesis of capsinoid is controlled by the Pun1 locus in pepper. Mol. Breeding 2013, 31, 537-548.

25. Stewart, C., Kang, B. C., Liu, K., Mazourek, M., Moore, S. L., Yoo, E. Y., et al. The Pun1 gene for pungency in pepper encodes a putative acyltransferase. Plant J. 2005, 42, 675-688 
26. Weber, N., Ismail, A., Gorwa-Grauslund, M., Carlquist, M. Biocatalytic potential of vanillin aminotransferase from Capsicum chinense. BMC Biotechnol. 2014, 14, 25.

27. del Rosario Abraham-Juárez, M., del Carmen Rocha-Granados, M., López, M. G., RiveraBustamante, R. F., Ochoa-Alejo, N. Virus-induced silencing of Comt, pAmt and Kas genes results in a reduction of capsaicinoid accumulation in chili pepper fruits. Planta 2008, 227, 681-695.

28. Ogawa, K., Murota, K., Shimura, H., Furuya, M., Togawa, Y., Matsumura, T., Masuta, C. Evidence of capsaicin synthase activity of the Pun1-encoded protein and its role as a determinant of capsaicinoid accumulation in pepper. BMC Plant Biol. 2015, 15, 93-103.

29. Stewart, C. J., Mazourek, M., Stellari, G. M., O'Connell, M., Lahn, M. Genetic control of pungency in C. chinense via the Pun1 locus. J. Exp. Bot. 2007, 58, 979-991.

30. Wyatt, L. E., Eannetta, N. T., Stellari, G. M., Mazourek, M. Development and application of a suite of non-pungency markers for the Punl gene in pepper (Capsicum spp.). Mol. Breeding 2012, 30, 1525-1529.

31. Arce-Rodríguez, M. L., Ochoa-Alejo, N. Silencing AT3 gene reduces the expression of $p A m t$, $B C A T, K a s$, and $\mathrm{Acl}$ genes involved in capsaicinoid biosynthesis in chili pepper fruits. Biol. Plantarum 2015, 59, 477-484

32. Prasad, B. C., Kumar, V., Gururaj, H. B., Parimalan, R., Giridhar, P., Ravishankar, G. A. Characterization of capsaicin synthase and identification of its gene (csyl) for pungency factor capsaicin in pepper (Capsicum spp.). Proc. Nat1. Acad. Sci. USA 2006, 103, 13315-13320.

33. Prasad, B. C. N., Gururaj, H. B., Kumar, V. Influence of 8-Methyl-nonenoic acid on capsaicin biosynthesis in in-Vivo and in-Vitro cell cultures of Capsicum Spp.. J. Agric. Food Chem. 2006, $54,1854-1859$.

34. Reddy, U. K., Almeida, A., Abburi, V. L., Alaparthi, S. B., Unselt, D., Hankins, G., et al. Identification of gene-specific polymorphisms and association with capsaicin pathway metabolites in Capsicum annuum L. collections. Plos One 2014, 9, e86393

35. Altúzar-Molina, A. R., Muñoz-Sánchez, J. A., Vázquez-Flota, F., Monforte-González, M., Racagni-Di, Palma. G., Hernández-Sotomayor, S. M. Phospholipidic signaling and vanillin production in response to salicylic acid and methyl jasmonate in Capsicum chinense J. cells[J]. Plant Physiol. Biochem. 2011, 49, 151-158

36. Ancona-Escalante, W. R., Baas-Espinola, F. M., Castro-Concha, L. A., Vázquez-Flota, F. A., Zamudio-Maya, M., Miranda-Ham, M. L. Induction of capsaicinoid accumulation in placental tissues of Capsicum chinense Jacq. requires primary ammonia assimilation. Plant Cell Tiss. Organ. Cult. 2013, 113, 565-570 
37. Gutiérrez-Carabajal, M., Monforte-González, M., Miranda-Ham, M., Godoy-Hernández, G. Vázpuez-Flota F. Induction of capsaicinoid synthesis in Capsicum chinense cell cultures by salicylic acid or methyl jasmonate. Biol Plantarum, 2010, 54, 430-434.

38. Kehie, M., Kumaria, S., Tandon, P. Manipulation of culture strategies to enhance capsaicin biosynthesis in cell cultures of Capsicum chinense Jacq cv. Naga King Chilli. Bioproc. Biosyst. Eng. 2014, 37, 1055-1063

39. Kehie, M., Kumaria, S., Tandon, P. Biotechnological enhancement of capsaicin biosynthesis in suspension and immobilized cell suspension cultures of Naga King Chili (Capsicum chinense Jacq.). Bioproc. Biosyst. Eng. 2016, 39, 205-210

40. Sudha, G., Ravishankar, G. A.. Influence of calcium channel $m f$ modulators in capsaicin production by cell suspension cultures of Capsicum frutescens Mill. Curr. Sci. 2002, 83, 480-484

41. Deng, M. H., Wen., J. F, Zhu, H. S., Zou, X. X. The hottest pepepr variety in China. Gene.t Resour. Crop Evol. 2009, 56, 605-608.

42. Collins, M. D., Wasmund, L. M., Bosland, P. W. Improved method for quantifying capsaicinoid in Capsicum using high performance liquid chromatography. HortScience 1995, 30, 137-139

43. Avanci, N. C., Luche, D. D., Goldman, G. H., Goldman, M. H. Jasmonates are phytohormones with multiple functions, including plant defense and reproduction. Genet. Mol. Res. 2010, 9, 484-505

44. Deng, M. H., Wen, J. F., Huo, J. L., Zhu, H. S., Dai, X. Z., Zhang, Z. Q., et al. Molecular cloning, sequence characterization of a novel pepper gene $N A D P-I C D H$ and its affect on cytoplasmic male sterility. Gene.t Mol. Res. 2012, 11, 3020-3031

45. Livak, K. J., Schmittgen, T. D. Analysis of relative gene expression data using real-time quantitative PCR and the 2(-Delta Delta C(T)) Method. Methods 2001, 25, 402-408.

46 Kim, J. S., Park, M., Lee, D. J., Kim, B. D. Characterization of putative capsaicin synthase promoter activity. Mol. Cells 2009, 28, 331-339

47. Bonfill, M., Mangas, S., Moyano, E., Cusido, R. M., Palazon, J. Production of centellosides and phytosterols in cell suspension cultures of Centella asiatica. Plant Cell Tiss. Org. Cult. 2011, 104, 61-67.

48. Frankfater, C. R., Dowd, M. K., Triplett, B. A. Effect of elicitors on the production of gossypol and methylated gossypol in cotton hairy roots. Plant Cell Tiss. Org. Cult. 2009, 98, 341-349

49. Prasad, B. C. N., Gururaj, H. B., Kumar, V., Giridhar, P., Ravishankar, G. A. Valine pathway is more crucial than phenyl propanoid pathway in regulating capsaicin biosynthesis in Capsicum frutescens mill. J. Agric. Food Chem. 2006, 54, 6660-6665 
Table 1. Primer pairs for RT-PCR and qRT-PCR

\begin{tabular}{|c|c|c|c|}
\hline gene & & Fwd 5'--3' & Rev 5'--3' \\
\hline \multirow{2}{*}{ CaPAL } & RT-PCR & TCATGGCATCAACAATTGCAC & CCGCCTAACAGATTGGAAGGGGAG \\
\hline & qRT-PCR & TTTGCCTATGCTGATGATACCTG & GCTGTTCACATTCTTCTCGCTTT \\
\hline \multirow{2}{*}{$\mathrm{CaCa} 4 \mathrm{H}$} & RT-PCR & CCCTAAAAGAAAACTCAT & TCAGATAGGCAGAACTTAC \\
\hline & qRT-PCR & TCAGATTCCTTCCATTCGGT & CTTTCTCCGTGGTGTCGAG \\
\hline \multirow{2}{*}{$\mathrm{CaCa} 3 \mathrm{H}$} & RT-PCR & ACCATGGCAA TTCCCTTAGC & CTAACAAGAGTAGTACATGC \\
\hline & qRT-PCR & AGTAGAGATGGAGCGGATCTGAT & AGCCTTGTTATGTTGTTGAAGGA \\
\hline \multirow{2}{*}{$\mathrm{CaCOMT}$} & RT-PCR & TCTTCTACTCTAGAATTTCCGAA & GGTTTTCTCAATAAATACAAGGA \\
\hline & qRT-PCR & AAACAAGCCATAGCCTAACTCAAAC & AAGTAGCAAGAAGCCTAAACATTCG \\
\hline \multirow{2}{*}{ CapAMT } & RT-PCR & AGAAATCTTGAAGGAATG & ATAGCACAAAGAGGAAAT \\
\hline & qRT-PCR & TTTCATTGCCGAACCAGTC & GTCCCAAGTCTTCCAAATCCA \\
\hline \multirow{2}{*}{$\mathrm{CaBCAT}$} & RT-PCR & CCTCTACCTAATCTGTTGCTTGC & GTAAAATAACTTTAAGACGATTCA \\
\hline & qRT-PCR & AAAGCGTTTAGAAGAGAGGATGG & GACAAGGAATGTGTACTCAGGTG \\
\hline \multirow{2}{*}{ CaKAS } & RT-PCR & TGAGAAGATGAGTAGTATTA & AGAAATTATGAGCTTGTGTT \\
\hline & qRT-PCR & ATGAGTTTGGTAGATGCGGGA & CGGTGTCAATTGTAACCTGAGG \\
\hline \multirow{2}{*}{$\mathrm{CaACL}$} & RT-PCR & ATCAATGGCTTCTATTACTG & AATACGACGAGTCTTACAG \\
\hline & qRT-PCR & ATCTCTTCCTTCAAGCACAACCA & TCCTCAAGTCCCATGACAATCTC \\
\hline \multirow{2}{*}{ CaFAT } & RT-PCR & ATGTTGTCTCGGGGGAGTTTT & CGCTAGTACTTAGGCAACAATGAA \\
\hline & qRT-PCR & ACCTCGTAACACCTAACAATAAACTTT & AGAGAGAGTAAGAGTAAGCAGCAAGT \\
\hline \multirow{2}{*}{ CaACYase } & RT-PCR & ATGGAAATCATTATTCTCTC & CATCTTTTTATGACTATTGC \\
\hline & qRT-PCR & CCAAACCAACACCТCСАAAC & CCAGCAAGCGGATAGAACA \\
\hline \multirow{2}{*}{$\mathrm{CaCS}$} & RT-PCR & GGAGGGTGTTAGGTGTATT & GACCGTAAACTTCCGTTG \\
\hline & qRT-PCR & CGCACAAGATTGGTGATGG & TTCTGTACGCACTCGTTGAGAT \\
\hline \multirow{2}{*}{ ACTIN } & RT-PCR & TGCAGGAATCCACGAGACTAC & TACCACCACTGAGCACAATGTT \\
\hline & qRT-PCR & TGCAGGAATCCACGAGACTAC & TACCACCACTGAGCACAATGTT \\
\hline
\end{tabular}


Table 2. The base composition of 11 genes

\begin{tabular}{|l|l|l|l|l|}
\hline gene & $\mathrm{A}$ & $\mathrm{G}$ & $\mathrm{T}$ & $\mathrm{C}$ \\
\hline $\mathrm{CaPAL}$ & $28.92 \%(623)$ & $24.74 \%(533)$ & $26.32 \%(567)$ & $20.01 \%(431)$ \\
\hline $\mathrm{CaCa} 4 \mathrm{H}$ & $27.73 \%(421)$ & $25.36 \%(385)$ & $28.26 \%(429)$ & $18.64 \%(283)$ \\
\hline $\mathrm{CaCa3H}$ & $25.65 \%(394)$ & $25.85 \%(397)$ & $24.87 \%(382)$ & $23.63 \%(363)$ \\
\hline $\mathrm{CaCOMT}$ & $27.26 \%(296)$ & $23.48 \%(255)$ & $29.01 \%(315)$ & $20.26 \%(220)$ \\
\hline CapAMT & $30.07 \%(415)$ & $22.25 \%(307)$ & $29.35 \%(405)$ & $18.23 \%(253)$ \\
\hline CaBCAT & $30.57 \%(354)$ & $23.14 \%(268)$ & $28.84 \%(334)$ & $17.44 \%(202)$ \\
\hline CaKAS & $28.77 \%(422)$ & $25.09 \%(368)$ & $27.33 \%(401)$ & $18.81 \%(276)$ \\
\hline CaFATA & $29.39 \%(328)$ & $25.72 \%(287)$ & $28.23 \%(315)$ & $16.67 \%(186)$ \\
\hline CaACL & $26.82 \%(107)$ & $23.56 \%(94)$ & $27.32 \%(109)$ & $22.31 \%(89)$ \\
\hline CaACYase & $32.31 \%(443)$ & $20.42 \%(280)$ & $29.39 \%(403)$ & $17.87 \%(245)$ \\
\hline CaCS & $30.16 \%(399)$ & $19.88 \%(263)$ & $30.23 \%(400)$ & $19.73 \%(261)$ \\
\hline
\end{tabular}

Table 3. The alpha helix, extended strand, beta turn and random coil of 11 prorein

\begin{tabular}{|c|c|c|c|c|}
\hline protein & Alpha helix & Extended strand & Beta turn & Random coil \\
\hline CaPAL & 360 & 94 & 66 & 197 \\
\hline CaCa4H & 208 & 80 & 41 & 176 \\
\hline CaCa3H & 226 & 87 & 41 & 157 \\
\hline CaCOMT & 137 & 71 & 37 & 116 \\
\hline CapAMT & 177 & 91 & 41 & 150 \\
\hline CaBCAT & 119 & 107 & 47 & 112 \\
\hline CaKAS & 137 & 123 & 54 & 174 \\
\hline CaFATA & 116 & 84 & 23 & 148 \\
\hline CaACL & 58 & 21 & 6 & 47 \\
\hline CaACYase & 181 & 98 & 39 & 138 \\
\hline CaCS & 185 & 67 & 43 & 145 \\
\hline
\end{tabular}




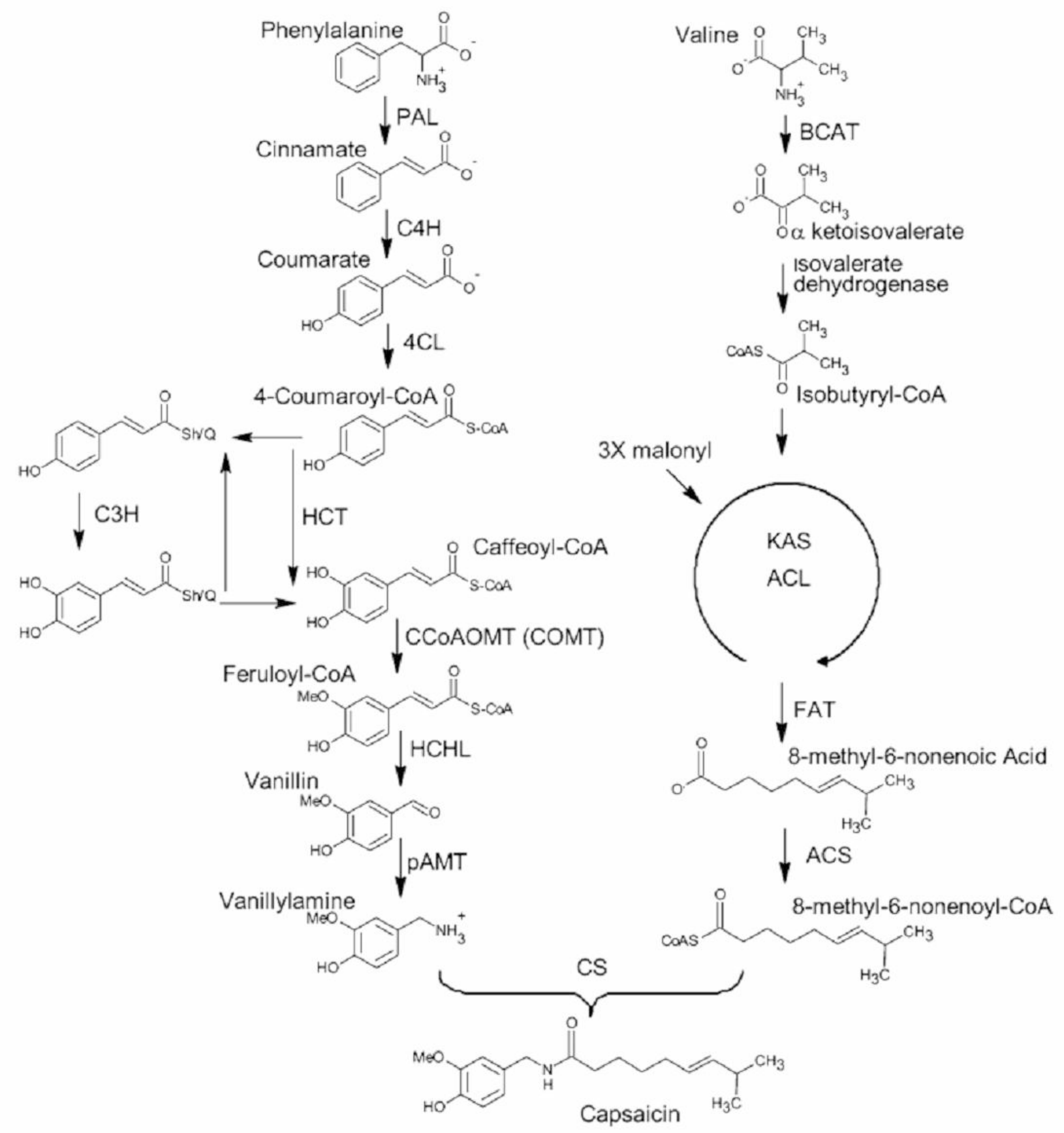

Fig. 1 Capsaicinoid biosynthetic pathway.

Fig. 1 Capsaicinoid biosynthetic pathway; 

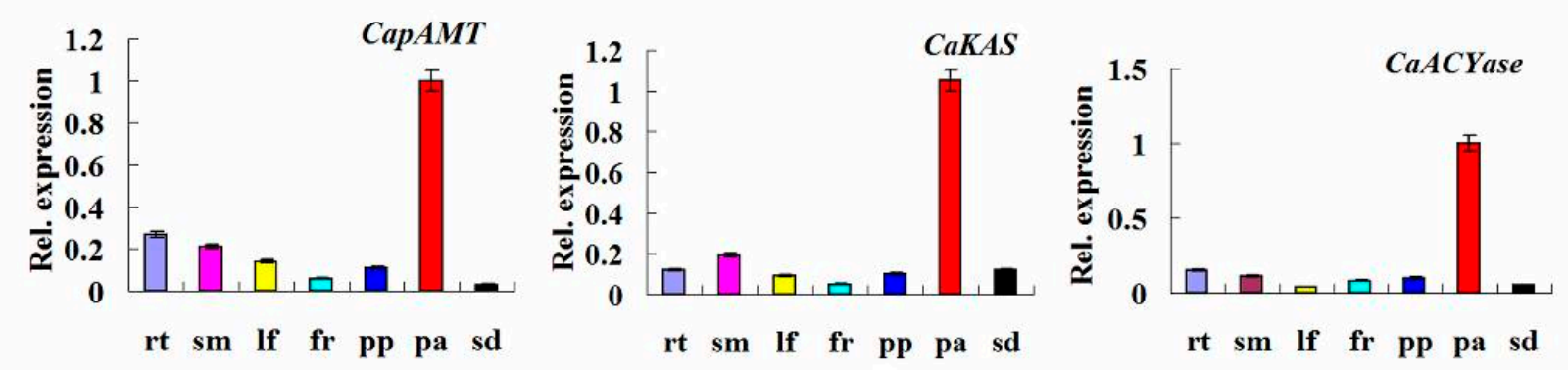

II
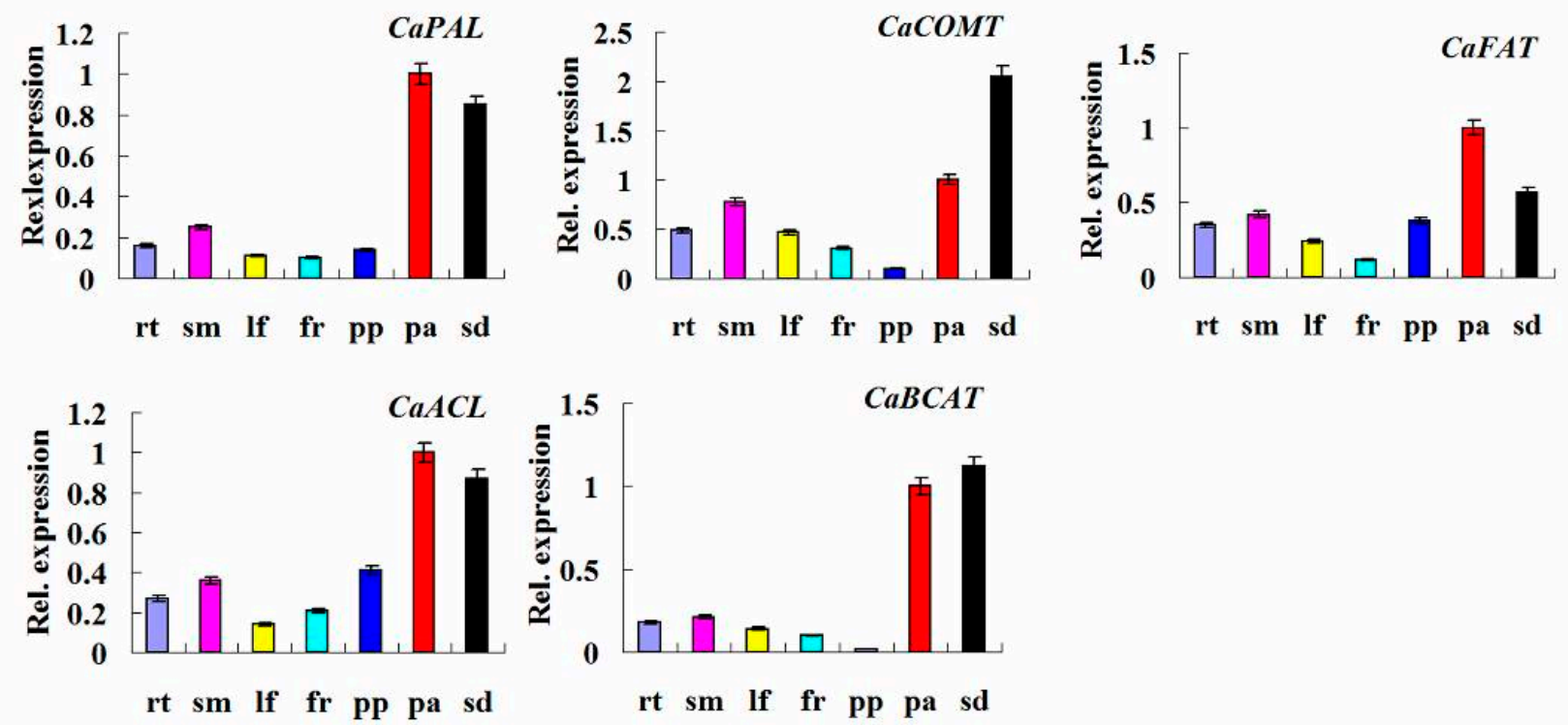

III

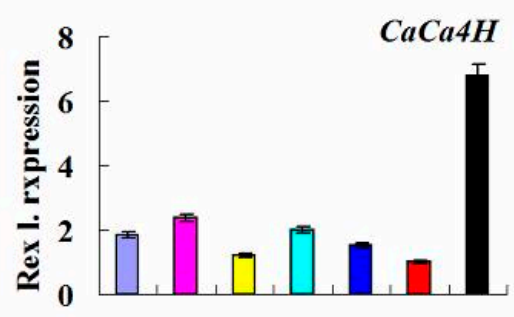

rt sm lf fr pp pa sd

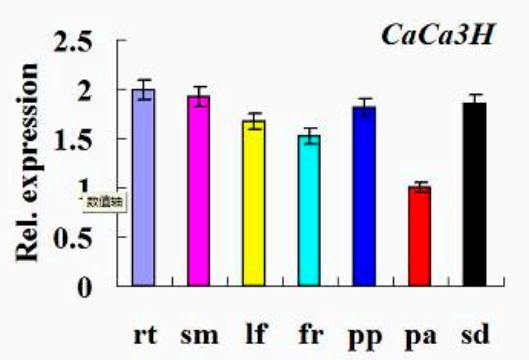

IV

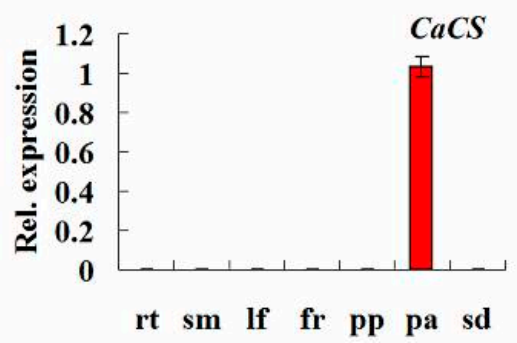

Fig. 2 Expression pattern of capsaicinoid biosynthesis genes by qRT-PCR method in different tissues (each data point represents the mean \pm SD of three replicates; values in graph indicate relative expression fold; rt denotes root; sm denotes stem; If denotes leaf; fr denotes flower; pp denotes pericarp; pa denotes placenta; sd denotes seed). 


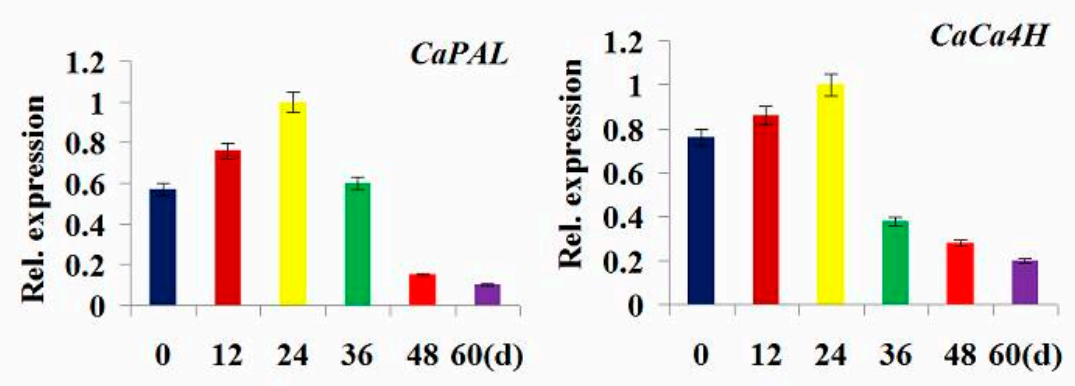

II
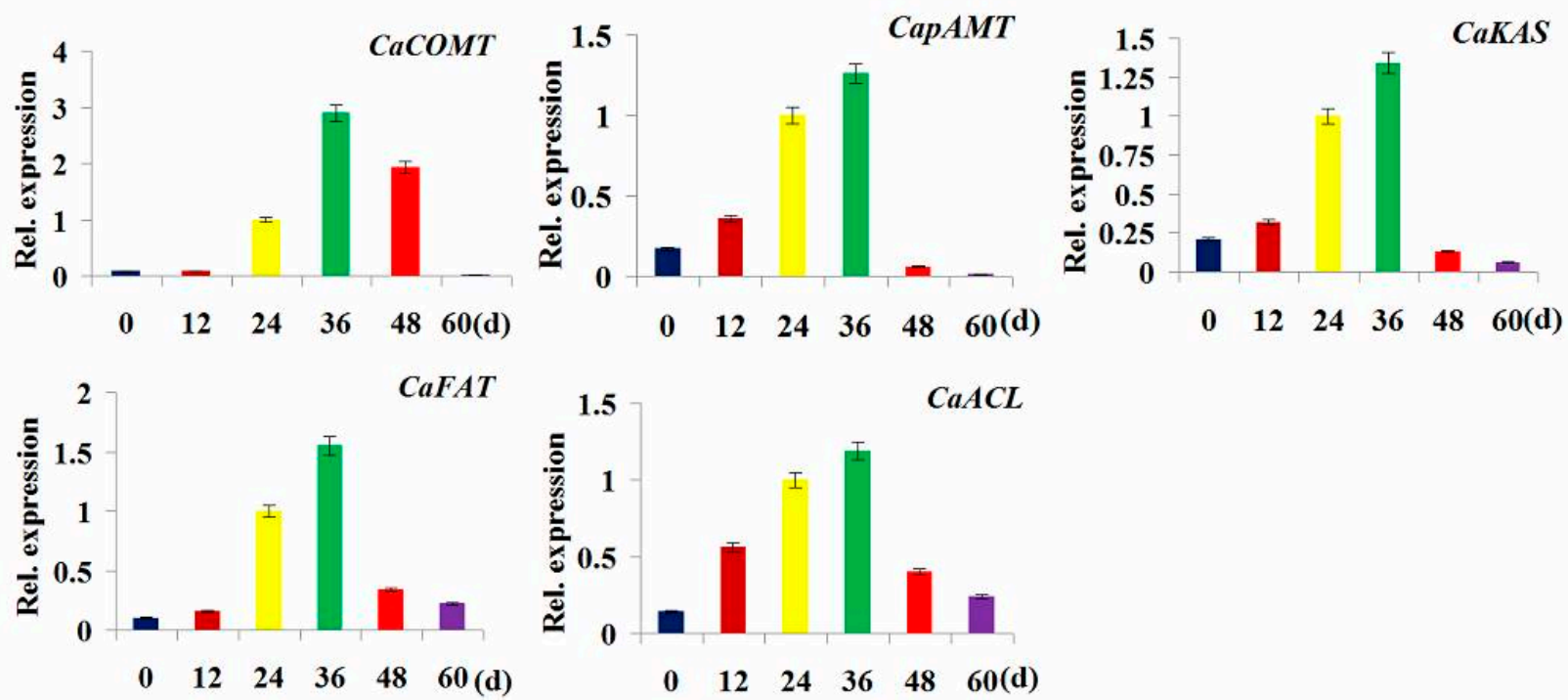

III
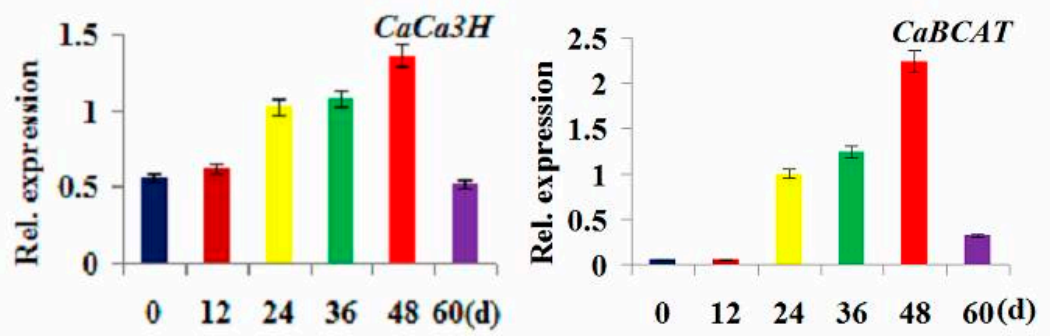

IV
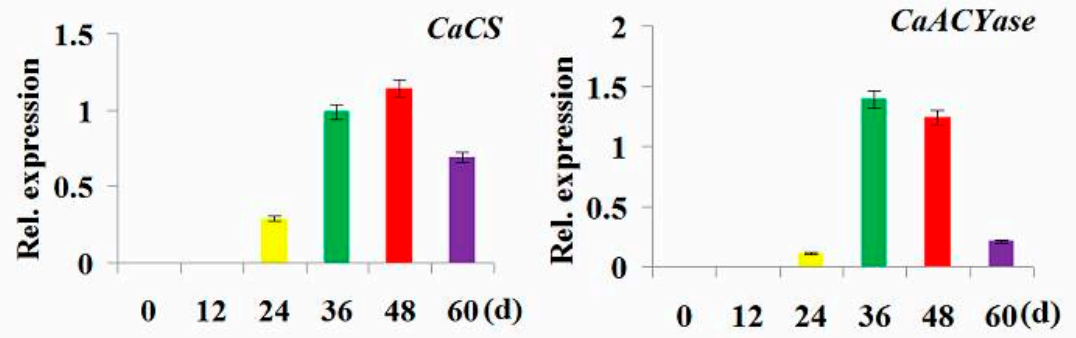

Fig. 3 Expression pattern of capsaicinoid biosynthesis genes by qRT-PCR method in different stage of development fruit 
I

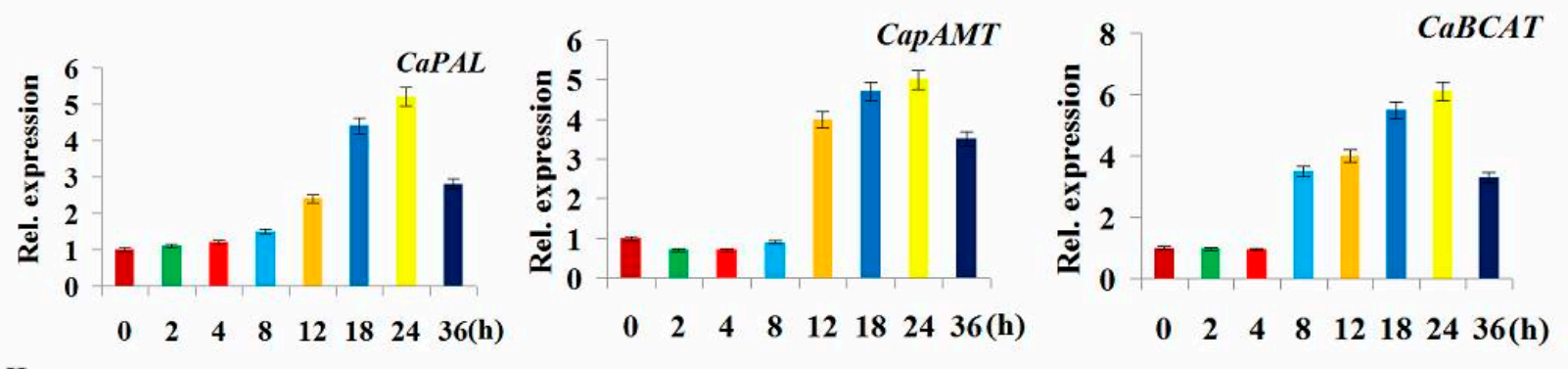

II
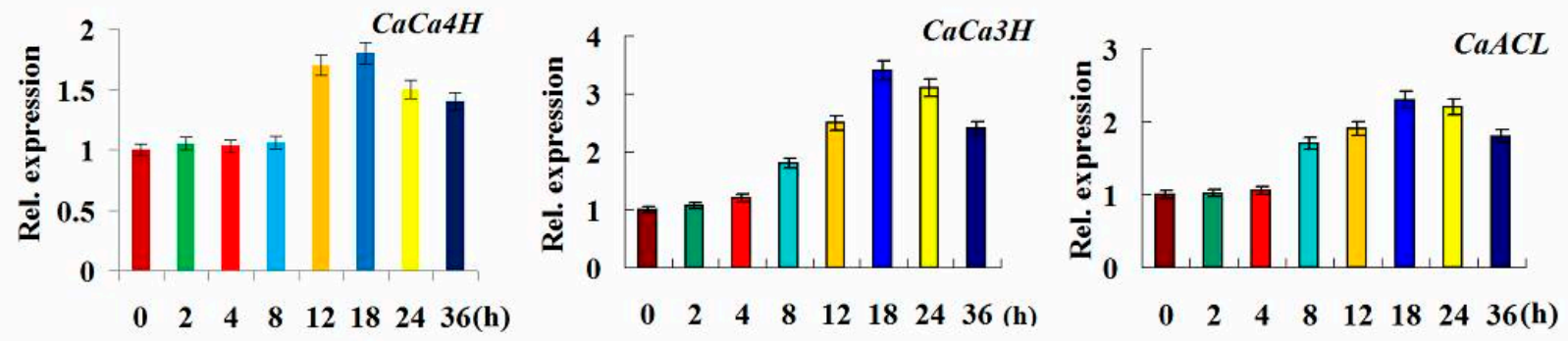

III
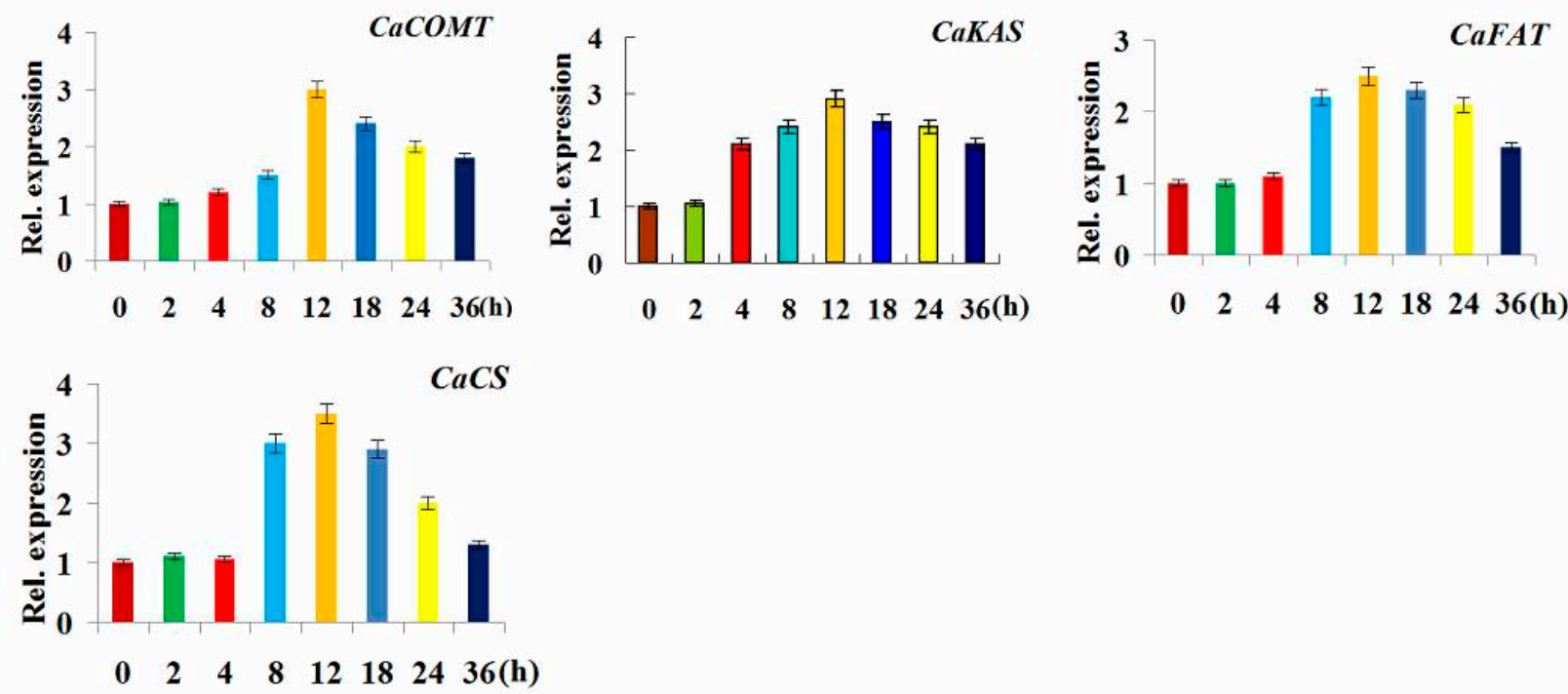

IV

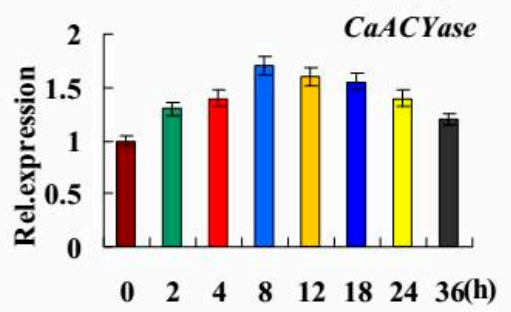

Fig. 4 Expression pattern of capsaicinoid biosynthesis genes under MeJA treatment by qRT-PCR method 
Table S1. The number of twenty kinds of amino acids, total number of negatively charged residues $(\mathrm{Asp}+\mathrm{Glu})$ and total number of positively charged residues (Arg + Lys) of the eleven proteins

\begin{tabular}{|c|c|c|c|c|c|c|c|c|c|c|c|}
\hline protein & CaPAL & $\mathrm{CaCa} 4 \mathrm{H}$ & $\mathrm{CaCa} 3 \mathrm{H}$ & CaCOMT & CapAMT & CaBCAT & CaKAS & CaFATA & $\mathrm{CaACL}$ & CaACYase & $\mathrm{CaCS}$ \\
\hline Ala (A) & 67 & 25 & 47 & 30 & 41 & 31 & 46 & 19 & 15 & 24 & 25 \\
\hline $\operatorname{Arg}(\mathrm{R})$ & 32 & 33 & 34 & 10 & 11 & 20 & 24 & 27 & 3 & 15 & 18 \\
\hline $\operatorname{Asn}(\mathrm{N})$ & 44 & 26 & 19 & 14 & 22 & 13 & 23 & 17 & 4 & 40 & 23 \\
\hline Asp (D) & 29 & 25 & 27 & 22 & 18 & 20 & 28 & 22 & 7 & 22 & 22 \\
\hline Cys $(C)$ & 13 & 3 & 5 & 10 & 6 & 6 & 9 & 8 & 4 & 6 & 13 \\
\hline $\mathrm{Gln}(\mathrm{Q})$ & 23 & 18 & 15 & 5 & 12 & 15 & 11 & 11 & 4 & 12 & 14 \\
\hline Glu (E) & 50 & 35 & 31 & 21 & 32 & 22 & 21 & 29 & 10 & 30 & 28 \\
\hline Gly (G) & 54 & 30 & 31 & 26 & 33 & 34 & 49 & 22 & 7 & 24 & 20 \\
\hline His $(\mathrm{H})$ & 17 & 13 & 17 & 10 & 11 & 1 & 10 & 8 & 1 & 8 & 9 \\
\hline Ile (I) & 40 & 32 & 25 & 18 & 25 & 27 & 39 & 21 & 11 & 34 & 21 \\
\hline Leu (L) & 77 & 55 & 53 & 33 & 45 & 30 & 32 & 32 & 11 & 55 & 49 \\
\hline Lys (K) & 41 & 37 & 27 & 21 & 33 & 25 & 27 & 22 & 11 & 28 & 30 \\
\hline $\operatorname{Met}(\mathrm{M})$ & 20 & 13 & 16 & 17 & 11 & 8 & 13 & 8 & 3 & 14 & 12 \\
\hline Phe (F) & 21 & 29 & 23 & 16 & 23 & 15 & 16 & 9 & 5 & 25 & 22 \\
\hline Pro (P) & 30 & 30 & 32 & 20 & 25 & 17 & 17 & 12 & 5 & 23 & 22 \\
\hline Ser $(\mathrm{S})$ & 54 & 22 & 23 & 24 & 32 & 29 & 41 & 34 & 14 & 33 & 45 \\
\hline Thr (T) & 39 & 20 & 22 & 21 & 27 & 20 & 26 & 7 & 7 & 21 & 20 \\
\hline $\operatorname{Trp}(\mathrm{W})$ & 4 & 8 & 11 & 5 & 6 & 3 & 3 & 10 & 0 & 4 & 3 \\
\hline Tyr (Y) & 15 & 10 & 17 & 10 & 19 & 21 & 17 & 29 & 0 & 8 & 13 \\
\hline Val (V) & 47 & 41 & 36 & 28 & 27 & 28 & 36 & 0 & 10 & 30 & 31 \\
\hline$(\mathrm{Asp}+\mathrm{Glu})$ & 79 & 60 & 58 & 43 & 50 & 42 & 49 & 51 & 17 & 52 & 50 \\
\hline (Arg + Lys) & 73 & 70 & 61 & 31 & 44 & 45 & 51 & 49 & 14 & 43 & 48 \\
\hline
\end{tabular}

Table S2. The formula, Ext. coefficienct, the instability index (II), aliphatic index, Grand average of hydropathicity of 11 induced protein

\begin{tabular}{|c|c|c|c|c|c|}
\hline Protein & formula & $\begin{array}{c}\text { Ext. } \\
\text { coefficient }\end{array}$ & $\begin{array}{c}\text { the instability } \\
\text { index (II) }\end{array}$ & $\begin{array}{c}\text { aliphatic } \\
\text { index }\end{array}$ & $\begin{array}{c}\text { Grand average of } \\
\text { hydropathicity }\end{array}$ \\
\hline CaPAL & $\mathrm{C}_{3418} \mathrm{H}_{5509} \mathrm{~N}_{959} \mathrm{O}_{1051} \mathrm{~S}_{33}$ & 45100 & $33.60 \mathrm{~S}$ & 91.99 & -0.157 \\
\hline $\mathrm{CaCa} 4 \mathrm{H}$ & $\mathrm{C}_{2638} \mathrm{H}_{4167} \mathrm{~N}_{719} \mathrm{O}_{722} \mathrm{~S}_{16}$ & 59025 & $48.29 \mathrm{U}$ & 95.68 & -0.251 \\
\hline $\mathrm{CaCa3H}$ & $\mathrm{C}_{2626} \mathrm{H}_{4081} \mathrm{~N}_{719} \mathrm{O}_{724} \mathrm{~S}_{21}$ & 86080 & $33.94 \mathrm{~S}$ & 89.16 & -0.210 \\
\hline CaCOMT & $\mathrm{C}_{1768} \mathrm{H}_{2760} \mathrm{~N}_{456} \mathrm{O}_{522} \mathrm{~S}_{27}$ & 43025 & $28.58 \mathrm{~S}$ & 85.90 & 0.029 \\
\hline CapAMT & $\mathrm{C}_{2300} \mathrm{H}_{3557} \mathrm{~N}_{587} \mathrm{O}_{672} \mathrm{~S}_{17}$ & 61685 & $47.71 \mathrm{U}$ & 85.47 & -0.140 \\
\hline CaBCAT & $\mathrm{C}_{1903} \mathrm{H}_{2997} \mathrm{~N}_{503} \mathrm{O}_{568} \mathrm{~S}_{14}$ & 48165 & $46.19 \mathrm{U}$ & 86.88 & -0.163 \\
\hline CaKAS & $\mathrm{C}_{2306} \mathrm{H}_{3674} \mathrm{~N}_{644} \mathrm{O}_{705} \mathrm{~S}_{22}$ & 42330 & $34.66 \mathrm{~S}$ & 87.56 & -0.072 \\
\hline CaFATA & $\mathrm{C}_{1832} \mathrm{H}_{2929} \mathrm{~N}_{525} \mathrm{O}_{570} \mathrm{~S}_{16}$ & 53900 & $44.18 \mathrm{U}$ & 83.50 & -0.453 \\
\hline CaACL & $\mathrm{C}_{612} \mathrm{H}_{1012} \mathrm{~N}_{162} \mathrm{O}_{196} \mathrm{~S}_{7}$ & 250 & $41.18 \mathrm{U}$ & 98.33 & 0.121 \\
\hline CaACYase & $\mathrm{C}_{2295} \mathrm{H}_{3637} \mathrm{~N}_{601} \mathrm{O}_{675} \mathrm{~S}_{20}$ & 34295 & $44.73 \mathrm{U}$ & 100.46 & -0.055 \\
\hline CaCS & $\mathrm{C}_{2194} \mathrm{H}_{3468} \mathrm{~N}_{582} \mathrm{O}_{656} \mathrm{~S}_{25}$ & 36620 & $37.46 \mathrm{~S}$ & 88.16 & -0.162 \\
\hline
\end{tabular}

(C) 2016 by the authors; licensee Preprints, Basel, Switzerland. This article is an open access article distributed under the terms and conditions of the Creative Commons by Attribution (CC-BY) license (http://creativecommons.org/licenses/by/4.0/). 